智能城市应用·2020 第3卷 第1期

Smart City Application.2020, 3(1)

\title{
1.2 保障档案资料的真实性
}

任何工程的实施过程都不可避免地会产生变动, 在很多情况下工程会因为一些外界条件因素产生阻碍。例如因环 境原因导致的工期延迟、工程故障、机械设备问题等。此类问题都直接影响到工程进度。如果没有施工监理的支持, 那么施工人员也无法按照监理工程师的要求来展开各项工作。而施工图纸作为主要的参考指标, 也需要通过监理过程 来将其与竣工档案保持一致。所以, 无论工程出现变更还是其它问题, 施工过程可以得到全方位的管控, 保障责任到 人, 也能保障竣工材料来自于施工现场, 维持其真实性和准确性。

\section{3 保障档案资料的完整性}

监理单位从工程招标开始直到竣工, 全过程的建立会直接将所有资料纳入建立范围之内, 当监理工程师按照工作 要求完成各项工作后, 就可以保障竣工的档案资料完整性。而监理单位的监理工程师本身是有相应的资格证书, 无论 是学历还是学科专业知识层次都普遍较高, 可以按照相关法律的要求来开展实践训练, 解决工程档案管理中可能出现 的不规范现象。

\section{4 保障档案资料的标识性}

标识性主要体现在对工程资料的日后利用与追踪, 因此施工监理可以实现这一目标, 在保障工程资料完整的同时, 通过及时归档管理，让信息可以快速地在电脑等设备中定位查询，随时获取想要获得的信息。

\section{2 当前工程竣工档案管理的主要问题}

\section{1 制度建设问题}

合理的档案管理制度是档案管理工作有效开展的保障。在目前的建设单位之中, 档案管理制度一般是按照施工监 理的要求进行一定的调整, 并按照有关条例, 结合自身情况来制定制度条例, 按照制度要求进行管理工作。另一方面, 大多数施工监理工作在工程开展之前都未提出具体要求, 未建立专业的规章制度, 也为后期的竣工档案资料管理工作 带来了隐患。例如未按照档案的内容要求进行归档, 使得一些重要资料未能按要求收集。

\section{2 竣工档案的完整性不足}

当前的工程建设周期较长, 工程档案也往往分散在不同的部门当中, 在工程竣工验收时可能会出现脱节情况。例 如有些参建单位已经完工, 但工程档案不全, 甚至某些档案已经丢失。此时便无法将所有参建单位的工程档案集中于 专门的管理人员手中, 给今后的工程质量评价、维护运行和修改带来了麻烦, 为工程质量的纠纷埋下伏笔。

\section{3 管理意识问题}

我国传统的竣工档案管理主要是围绕验收阶段运行, 负责档案的收集和整理工作。但这种传统档案的理念具有一 定的局限性, 不利于档案的深度开发和利用。很多人员还停留在为建设方提供档案的定期服务经营模式。在未来的工 作当中, 档案管理人员也应该与时俱进地开展产品服务, 实现理念的创新。

\section{3 施工监理过程中如何提升竣工档案资料质量}

整体来看, 如何提升竣工档案资料的管理质量应该围绕三个阶段展开。例如图 1 所示。

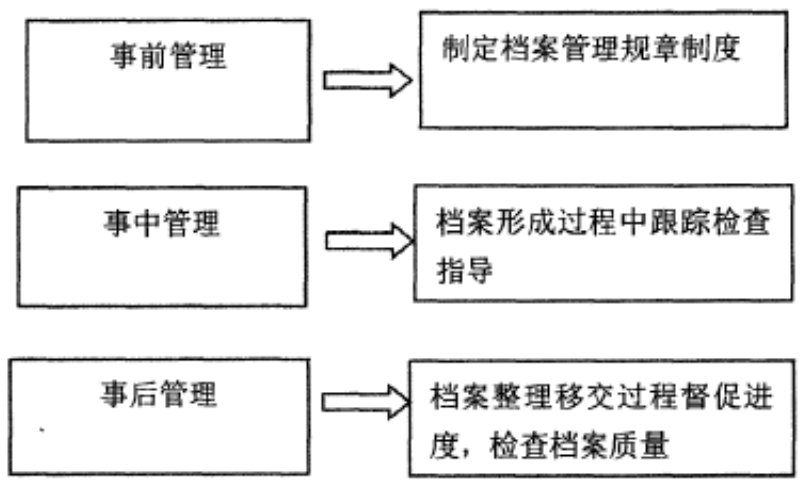

图 1 全过程监理方法

\section{1 事前档案管理意识的建立}

人员是实施管理的主体, 工程监理工作中必然也涉及到竣工档案的编制收集和整理, 例如根据《建筑工程资料管 理规程》来将工作规范化, 走向法制化轨道。在建立环节中, 要注重竣工档案的开发和利用, 具有明确的档案资料管 理意识。监理单位也需要通过一定的措施和手段来进行编制, 在各项决策过程中将重点纳入其中, 给予应有的重视程 度。此外, 应该及时地报告档案资料管理中的困难和问题, 明确未来施工监理的主要任务。必要时还应该对人员开展 
培训工作, 帮助人员树立管理意识, 组织监理工程师和施工单位共同学习竣工文件的编制要求等, 从而提升后期归档 的质量。

\section{2 竣工档案管理制度的构建}

工程竣工档案的管理本身是一个系统化的工程, 包括工程竣工档案的编制、收集和管理全过程, 每个过程之间具 有明确的联系, 并相互影响和制约。其系统性的特点也决定了其需要一套完善的工作程序和规则进行约束。具体来看, 工程竣工档案建设工作需要在施工监理过程中符合适用要求, 让适用具有可操作性, 以便于合理地发挥制度的指导和 规范性作用。另外，对竣工文件的收集、归档工作等都需要落实到位，施工任务和竣工文件的编制工作可以同步开展。 在事中控制环节, 要按照工程实际进度对工程项目资料进行全过程同步检查, 从制度建设中抓住工程建设的关键验收 阶段, 例如地基基础验收阶段、主体验收阶段、隐蔽工程验收阶段等, 开展经常性检查, 定期地了解当前的档案中可 能存在的问题并采取有效的解决措施。必要时, 对存在的问题提出明确的整改期限, 在最终竣工验收前检查其落实情 况，给出验收意见，最终将所有问题整理收集，作为典型案例，也可以督促其它单位进行改正。

\section{3 良好的监理执行力}

切实可行的制度建设要求下, 我们需要有着严格的执行标准, 将制度的落实和理想工作实现进行结合。监理部门 应该结合地方档案管理规程, 按照竣工档案的管理制度对人员进行监理, 让其能够及时推进和稳定档案资料的检查、 监督工作。为了确保档案的真实完整性, 在工程开工阶段就需要监理工程师按工程节点将所有资料进行编制计划, 亲 自把关, 直至所有信息都具有规范性并符合要求。各施工技术人员在施工过程中也应将各种工程的单项材料进行积累, 作为编制工程竣工文件的主要依据。

\section{4 结语}

通过研究, 不难看出施工监理对于工程竣工档案资料质量提升的现实作用, 也证实了相应的制度建设是完全可行 的, 能够在竣工资料的归档管理等各项工作中发挥应有的效果。在今后的工作中, 我们也应深刻认识到施工监理部门 的后续职责，以便于在执行过程中避免出现相似的问题，确保竣工文件的数量、质量。

\section{[参考文献]}

[1]刘肇欢.水土保持工程施工阶段工程档案存在的问题及解决对策 [J].中国水土保持,2019 (09): 27-28.

[2]陈炳新.城市轨道交通工程档案精细化管控研究——以广州地铁为例 [J]。城建档案, 2019 (08) : 48-50.

[3] 赵新宇. 重大建设项目档案管理流程及规范探讨——以昆明新机场建设项目为例 [J]. 云南档案, 2018(10): 56-60.

[4] 庄品琨.企业投资建设工程档案管理工作中存在的问题及对策 [J]。内蒙古煤炭经济, 2011(03) : 11-13.

作者简介: 卢运飞(1974-), 女, 工程档案管理专业, 现就职于中海油能源技术开发研究院有限责任公司。周红伟 (1987-), 男，土建监理工程师，现就职于北京双圆工程监理咨询有限公司。 


\title{
浅谈智慧社区的弱电智能化系统建设
}

郎海永 陈俏娟

创业慧康科技股份有限公司，浙江 杭州 310052

[摘要]住宅小区的弱电系统是小区智能化的核心，主要包括视频监控、入侵报警、出入口控制、停车场管理、电子巡查、楼 宇可视对讲、信息发布、建筑智能化等系统。工程建设的成败主要决定于设计的系统完整、前瞻性, 施工单位的深化设计技 术水平和施工管理水平。

[关键词]智慧社区; 智能化; 系统建设

DOI: 10.33142/sca.v3i1.1539 中图分类号: TU855 文献标识码：A

\section{Talking about the Construction of Weak Current Intelligent System in Smart Community}

LANG Haiyong, CHEN Qiaojuan

B-Soft Co., Ltd., Hangzhou, Zhejiang, 310052, China

\begin{abstract}
The weak current system of residential area is the core of intelligent residential area, mainly including video monitoring, intrusion alarm, entrance and exit control, parking lot management, electronic patrol, building visual intercom, information release, building intelligent and other systems. The success or failure of the project construction mainly depends on the integrity and foresight of the design system, the level of deepening design technology and construction management of the construction unit.
\end{abstract}

Keywords: smart community; intelligence; system construction

现在的社会发展越来越快, 人们的经济水平也在不断的提高, 并且对于生活品质要求也在不断的提高, 弱电智能 化系统在智慧社区中越来越重要, 它改善了社区人们的生活居住环境, 也提升了社区的管理水平。随着技术手段的不 断变革, 人们需求的不断提高, 对于智慧社区弱电智能化系统建设的研究很有现实意义。

\section{1 智慧社区的概念}

智慧社区其实质就是运用线下最前沿的智能化技术，并结合高水平的通信技术，将民众生活的环境、教育、娱乐 等公共以及商业活动资源进行整合, 并实施统一管理。围绕综合性信息服务平台为核心，借助最前沿的基础设施建设 工作，并运用当下最前沿的社区管理方式方法，创造智能化和综合性为一体的社区管理和服务的最新型的一种模式 ${ }^{[1]}$, 其目的就是为民众创造高水平的生活环境。

\section{2 系统设计遵循的原则}

2. 1 先进性

应该选择利用最前沿切实可行的技术以及综合性能较强的机械设备和产品。整个系统可以充分的展示出现如今智 能弱电工程的整体水平，为后续的系统完善创新创造良好的基础。

2.2 成熟性和实用性

各子系统设计的时候应采用先进、成熟、可靠的产品。系统应能充分发挥各设备的先进功能, 操作方便, 维护简 单, 便于管理。

\section{3 灵活性和开放性}

系统需要具备良好的综合性, 并且能够拥有良好的兼容性和互联性。

\section{4 集成性和可扩展性}

系统设计需要充分的结合实际情况和需求，在保证正常稳定运行的基础上，不断的进行创新。

\section{5 模块化和标准化}

借助最前沿的数字化、科学化的专业技术来实施信息的收集处理。融合当前世界最前沿的科学技术，对各个分支 系统进行升级完善, 从而提升系统的适应性 ${ }^{[2]}$ 。

\section{6 安全性和可靠性}

始终把系统的安全性和可靠性放在第一位。在系统设计时应选用安全性能好和可靠性高的设备。在系统集成平台 设计时应考虑多级管理权限的系统。

\section{7 互操作性能}

系统应有很好的互操作性能, 充分保证管理者和使用者的可靠、方便、高效、安全的操作运行。 